\title{
The Impact of e-Banking Practices on Five Selected Universal Banks
}

\author{
Rodolfo S. Vargas, Ph.D. \\ Assistant Professor, Department of Project Management and Information Technology, College of Financial Sciences,
}

AMA International University-Bahrain, Salmabad, Kingdom of Bahrain

\begin{abstract}
The impact of technology has made strategic and competitive advantage of universal banks in a real time environment on the efficient and real time processing of bank data that eventually increase the banks' income. This is a new way of channel of accessing and doing transactions in banking industry who embraced the online banking as a new paradigm of communication and online transactions. The new technology where created so that the clients can access their accounts without delay anywhere and everywhere twenty four by seven in their own convenience. This kind of traditional transaction normally done inside the banks premises. In this paper, the researcher aims to recommend a new model of computing ROI as a function of three Independent variables like internet banking compliance, ratio of the bank's number of branches to the number of branches of all the five banks and ratio of bank's loan to its deposit liability were the factors contributors that affect the ROI. The ROI was based on Dupont formula where these three variables were being studied. The researcher also used multi-regression in predicting the effect, extent and impact of three independent variables in banking practices on five universal banks in the Philippines. This work is a contribution in the ongoing research towards adaptation of ROI model based on Dupont formula using data mining.
\end{abstract}

Keywords: e-banking, Internet Banking Compliance, Ratio-to-Total Branches, Ratio of Lending to deposit liabilities.

\section{INTRODUCTION}

Poor services and the desire to increase market base were primary reasons why banks changed from traditional activities to modern one. The convergence of information and communication technology in reaching clients without building new physical branches are used now by the banking industry to transfer information from one place to another and to make available immediately to clients information either in an office or at home. The changing life style of customers led to real time banking operation in order to satisfy the customers' desire for convenience. Globalization in the banking industry is perhaps more focused on the profit to be made and that may be the reason why banks are becoming more astute in their approaches to services to clients in order to achieve maximum profit. Local bankers foresee that more foreign banks will enter the country. They will bring their portfolio of modern products and services with them, as well as their global sourcing of funds. The Philippine banking industry may have realized the need to modernize at least some of their services to insure that prime clients are not lost to foreign financial institutions.

The banking industry as other organizations that render service - it must be open, speedy, and efficient. Electronic online transmission with regard to data processing of documents is an acclaimed approach to achieving efficiency. Traditionally, a person goes to the bank personally for the safekeeping of their money. The Internet is opening up new servicing channels and opportunities for local banks to compete with other banks locally and globally. However, barriers still exist in the servicing of the information provided online. This research will determine the relative effects of increase in the number of branches, ratio of loans to deposit liabilities and stage of implementation of the e-commerce law in terms of improving the performance of the banking industry measured in changes in their returns on investment (ROI). To the bank, the e-banking offers a more cost-effective means of delivering these routine functions and frees branch personnel for selling services with a greater return. Entry into the e-banking arena is thus no longer complex from the standpoint of either operations or marketing. Attention is now focused on how an e-banking strategy integrates with an overall retail and corporate service strategy and how e-banking can be positioned to increase bank profits. Banks generally view an e-banking program in terms of how it will impact in internal operating cost and what effect it will have on market share in terms of bank efficiency. Reducing cost is a primary reason that is common to large banks with extensive investments in branch facilities and personnel.

\section{RESEARCH METHODOLOGY}

This chapter presents the manner in which the data was validated as to accuracy before they were subjected to analysis. Hence, the following steps in the research process were taken into consideration:

1. Research Design:

a) The study involved the use of triangulation via the logico-cognitive-validation [Uma Sekaran] involving the data measurements and the assumed qualitative relationship between the dependent variable $\mathrm{Y}$ and the independent variables $\mathrm{X}_{1}, \mathrm{X}_{2}$ and $\mathrm{X}_{3}$ by using "factorial design"; and b) The study uses a Descriptive-cumpredictive design;

2) The Respondents of the Study as to the manner of selection; 
3) Instruments used in the gathering of primary and and its "goodness-of-fit" which was addressed in the secondary data, such as the questionnaire and the financial documents, respectively;

4) Procedure in Data Gathering; and

5) The Statistical Treatment of the research data.

In order to determine the validity or accuracy of the data measurement and the validity of the qualitative relationship between the dependent variable and the independent variables, triangulation was employed through the following:

1. Data measurement through difference in data-source; one using interviews and the other using secondary data (similarity of results using the two different sources establishes the validity of the data measurements). What is the validity of the data measurements by using two different sources of data; namely, through primary data gathering using interviews and through the use of secondary data sources such as the financial statements or statements-of-condition of the banks?

The data on the dependent and independent variables (Please see Appendix I) as gathered from bank documents such as their financial statements were validated by the authorized bank respondents upon interview.

2) validation of the assumed qualitative relationship of the independent-variable-data to the dependent-variable-data by using "factorial design" (When the respondents' $\mathrm{Y}^{\mathbf{0}}$ values [dependent variable] of zero fall within the cubes where internet-banking is zero and when the respondents' $\mathrm{Y}^{\mathbf{o}}$ values of one fall in the cubes where internet-banking is one in the "factorial design's three-dimensional matrix", then the dependence of the $\mathrm{Y}^{\mathbf{0}}$ variable on the independent variable $\left(\mathrm{X}_{1}^{\mathbf{o}}\right)$ internet-banking is established qualitatively. Further, when the respondents' $\mathrm{Y}^{\mathbf{0}}$ values of zero fell within both the zero and one values of $\mathrm{X}_{2}{ }^{\circ}$ (bank's number of branches to total of all banks' branches) , then regardless of whether or not there is a change in $\mathrm{X}_{2}{ }^{\mathbf{}}$, the respondents' $\mathrm{Y}^{\mathbf{0}}$ remained unchanged; hence, $\mathrm{X}_{2}{ }^{\circ}$ had no effect on $\mathrm{Y}^{\mathbf{0}}$. Similarly $\mathrm{X}_{3}{ }^{\circ}$ (ratio of lending to deposit liability) has no effect on $\mathrm{Y}^{\mathbf{0}}$ when the values of $\mathrm{Y}^{\mathbf{0}}$ remain unchanged when the values of $\mathrm{X}_{3}{ }^{\mathbf{0}}$ change. Worse is when one or two of the banks will show a downward change in their $\mathrm{Y}^{\mathbf{0}}$ value when the value of $\mathrm{X}_{3}{ }^{\mathbf{0}}$ changes from zero to one; thus, showing an inverse relationship. [Kinnear and Taylor, Marketing Research -An Applied Approach, 1991)

b) descriptive-cum-predictive design was employed. The descriptive statistic of the mean and the sample's standard error as a measure of its variability were employed. On the matter of the pertinent descriptive statistic of the dependent variable Y (ROI) and each of the independent variable Xs (internet-banking-compliance-of-each-bank, ratio-of-each-bank's-no.-of-branches-to-total-branches-ofall-five-banks, ratio-of-each-bank's-loans-to-its-depositliability), the five banks' mean and the standard error of the $\mathrm{Y}$ values(dependent variable) was used. Since the descriptive statistic of the independent variables (Xs,) which were to be translated to standardized units of their standard errors, needed the computation of the latter in preparation for the computation of the multiple regression problem statement items number one and two, then since such measurement has been addressed there, it need not be explicitly restated here.

What is the pertinent descriptive statistic (mean and standard error) of the $\mathrm{Y}$ values (dependent variable)? Since the descriptive statistic of the independent variables (Xs) --which were to be translated to standardized units of their standard errors-- needed the computation of the latter in preparation for the computation of the multiple regression which is addressed in problem numbers four and five , then such measurement is already addressed and need not be explicitly restated here.

Hence, descriptions of the five sample private universal and commercial banks in terms of the following were in order: their $\mathrm{Y}^{\circ} \mathrm{s}$ * mean and standard error counted in terms of the number of Chebyshev's factor " $k$ "

* The $\mathrm{Y}^{\circ} \mathrm{s}$ are the five banks' ROIs expressed in terms of their standard error which is a physical translation of the confidence interval normally expressed in percentage:

Figure 2 Translation of the Confidence Interval Normally Expressed in Percentage

$$
\mathrm{Y}^{\mathrm{o}} \pm(\mathrm{k}) \mathrm{s} / \sqrt{ } \mathrm{n}
$$

Where:

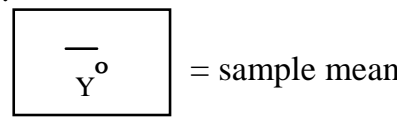

$\mathrm{k}=$ the translated confidence interval in terms of Chebyshev's factor for counting the number of standard error units

$\mathrm{s}=$ standard error (estimate of the population standard deviation)

$\mathrm{n}$ = sample size

The sample mean on $\mathrm{Y}^{\circ}$ and the " $\mathrm{s}$ " were obtained as follows:
BANK $\quad Y^{\circ}$
A $-0.9406-0.00002-0.940620 .88476$
B $-0.6466-0.00002-0.646620 .41812$
C $\quad-0.4997-0.00002-0.49972 \quad 0.24972$
$\mathrm{D}+0.6760-0.00002+0.67602 \quad 0.45700$
$\mathrm{E}+1.4108-0.00002+1.410821 .99041$

0.0001

4.00001

Sample

$\begin{aligned} \text { mean of } \mathrm{Y}^{\mathrm{o}} \overline{\mathrm{X}} \frac{0.0001}{5}=0.00002 & \\ \text { variance } & =\frac{4.00001}{\mathrm{n}-1}=\frac{4.0001}{5-1} \\ & =1.0000025\end{aligned}$

(s)standard error $=\sqrt{ }$ varianc

$=\sqrt{ } 1.0000025$

$=1.00000125$ 
Chebyshev's factor " $\mathrm{k}$ " is obtained in the following manner:

$1-1=$ Confidence Level in percent to be

$\mathrm{k}^{2}$ given arbitrarily by the researcher

$1-1=0.95 ;-1=0.95-1 ;-1=-0.05$

$\mathrm{k}^{2} \quad \mathrm{k}^{2} \quad \mathrm{k}^{2}$

$\begin{array}{ll}-1 & =\mathrm{k}^{2} ; \sqrt{-1}=\sqrt{-0.05} \\ -0.05 & \sqrt{\mathrm{k}^{2}} ; \sqrt{ } 20=\mathrm{k} ; 4.47=\mathrm{k} ; \\ 4.5 \approx \mathrm{k}\end{array}$

Accordingly, $\overline{\mathrm{X}}=0.00002 ; \mathrm{k}=4.5$;

$\mathrm{s}=1.00000125 ; \mathrm{n}=5$

Hence, $\bar{X}+(\mathrm{k})(\mathrm{s} / \sqrt{ } \mathrm{n})=0.00002+(4.5)$

$(1.00000125 / \sqrt{ } 5)=2.00903$
$\mathrm{X}-(\mathrm{k})(\mathrm{s} / \sqrt{ } \mathrm{n})=0.00002$

$(1.00000125 / \sqrt{ } 5)=2.00883$

What is the validity of the assumed data relationships in terms of the independent-variable-data being qualitatively related to the dependent-variable-data?

The factorial design in figure III validates approximately the dependence of $\mathrm{Y}^{\circ}$ (ROI standardized in terms of the number of its own standard error) on its erstwhile alleged explanatory or independent variables. How? In the "factorial design's three-dimensional matrix" of the immediately following table, when the respondents' $\mathrm{Y}^{\mathbf{0}}$ values [dependent variable] of zero fell within the cubes where internet-banking is zero and when the respondents' $\mathrm{Y}^{\mathbf{0}}$ values of one fell in the cubes where internet-banking is one as in the case of Bank C's Y-value of zero where the value of internet banking is zero and Bank D and E's $\mathrm{Y}$-values of one where internet banking has the value one , then the dependence of the $\mathrm{Y}^{\mathbf{0}}$ variable on the independent variable $\left(\mathrm{X}_{1}{ }^{\mathbf{}}\right)$ internet-banking is established qualitatively. Further, when the respondents' $\mathrm{Y}^{\mathbf{0}}$ values of zero fell within both the zero and one values of $\mathrm{X}_{2}{ }^{\circ}$ (bank's number of branches to total of all banks' branches) as in the case of banks $\mathrm{A}$ and $\mathrm{C}$, then regardless of whether or not there is a change in $\mathrm{X}_{2}{ }^{\mathbf{0}}$, the respondents' $\mathrm{Y}^{\mathbf{0}}$ remained unchanged; hence, $\mathrm{X} 2^{\circ}$ had no effect on $\mathrm{Y}^{\mathbf{0}}$. Similarly $\mathrm{X}_{3}{ }^{\mathbf{0}}$ (ratio of lending to deposit liability) had no effect on $\mathrm{Y}^{\mathbf{0}}$ because the values of $\mathrm{Y}^{\mathbf{0}}$ remain unchanged when the values of $\mathrm{X}_{3}{ }^{\mathbf{0}}$ changed as in the case of banks $\mathrm{E}$ and D.

Worse is the case of Bank B since when the value of $\mathrm{X}_{3}{ }^{\mathrm{o}}$ changed from zero to one, the $\mathrm{Y}^{\mathbf{0}}$-value one of Bank $\mathrm{E}$ changed to a $\mathrm{Y}^{\mathbf{0}}$-value zero of Bank B; thus, showing an inverse relationship. [Kinnear and Taylor, Marketing Research -An Applied Approach, 1995)

Regarding the prescriptive aspect of the research design, the matter of determining simultaneously which of a given alleged explanatory or independent variables has a greater degree of relationship with the dependent variable, the (DVLMR) Dummy Variable Linear Multiple Regression was used. In order to achieve the aforesaid objective of knowing which of the alleged explanatory variables has a greater degree of relationship with the dependent
Figure III

Factorial Design On The Dependent Variable ROI and the Independent Variables e-Banking Compliance, Ratio of Each Bank's No. of Branches To The Total of The Five Banks' No. of Branches, and Ratio of the Five Banks' Loans To Their Deposit Liabilities

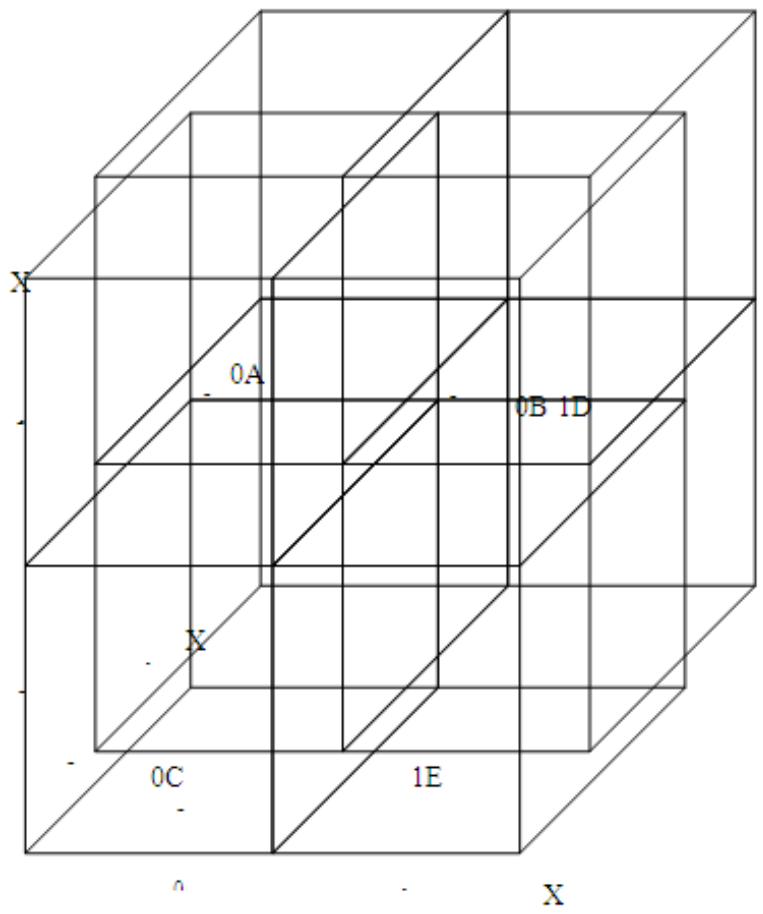

variable it was necessary to transform the natural values of $\mathrm{Y}(\mathrm{ROI})$ and the various $\mathrm{X}$ values by their respective standard deviations or their estimates in terms of their samples' standard error values. (Kinnear and Taylor, Marketing Research, (1987), pp. 544-545.)

\section{The Respondents of the Study as to the manner of} selection:

The researcher used primary data provided by the authorized employees of the five private universal banks in the Philippines. He sought the approval of managers to allow the employees to give the necessary data by means of answering the questionnaires provided by the researcher. The respondents were the people considered to be the most appropriate source of data in terms of the objectives of the study. The secondary data-sources for validating the questionnaire responses were the financial statements (Statements of Condition) of the banks.

\section{Sample of the Study:}

Though thirty banks were authorized to engage in ebanking only nineteen banks established e-banking facility. Hence, the researcher fielded nineteen questionnaires to cover the universe of respondents. However, only five responded among the nineteen banks.

Hence, the number of standard errors had to be reckoned in terms of Chebyshev's Theorem whereby data variability can be measured despite the number of respondents being less than thirty through the equation $1-1 / \mathrm{k}^{2}=$ Desired Confidence Level, where " $k$ " stands for the number of standard errors from the sample population's mean. 
International Advanced Research Journal in Science, Engineering and Technology

Vol. 3, Issue 3, March 2016

Table XIV Philippine Universal Banks As to Total Resources (with internet banking)

\begin{tabular}{|l|c|}
\hline Bank Code & Total Asset \\
\hline A & P 460,287,086,000 \\
\hline B & $401,706,000,000$ \\
\hline C & $294,711,122,000$ \\
\hline D & $101,730,295,000$ \\
\hline E & $87,450,784,437$ \\
\hline
\end{tabular}

Chebyshev's Inequality and Confidence Intervals for the Mean:

Chebyshev's theorem was used so as to describe the sample of 5 banks in terms of its mean and the sample's standard error.

"When the sample is small $(\mathrm{n}<30)$ and the population is assumed not to be normally distributed, neither the normal probability distribution nor at distribution can be used for constructing a confidence interval. However, a general theorem developed by the Russian mathematician Chebyshev is useful.

Chebyshev theorem: The proportion of measurements in a set of data that lies within $\mathrm{k}$ standard deviation of the mean is not less than $1-1 / k 2$, where $k \geq 1$.

As applied to the sampling distribution of a mean, the probability that a sample mean will lie within $\mathrm{k}$ standard error units from the population mean is

$\mathrm{P}(\mathrm{X}-\mu \leq \mathrm{k} \sigma \mathrm{x}) \geq 1-1 / \mathrm{k} 2 \quad$ (figure 8.10)

Formula (8.10) is generally referred to as Chebyshev's inequality. Note that it is based on the assumption that $\sigma \mathrm{x}$ is known. If $\sigma$ is not known then $s_{x}$ can be used in its place, but with some risk because of the fluctuation of this value for small samples.

Chebyshev's inequality is in fact rarely used for constructing confidence for the mean, but it is the only appropriate method given a population that is decidedly non-normal and a sample that is small $(\mathrm{n}<30)$.

In using Chebyshev inequality in conjunction with interval estimation, the procedure is to set $1-1 / \mathrm{k} 2$ equal to the desired degree of confidence, solve for $\mathrm{k}$, and then construct the interval using one of the following formulas, according to whether or not $\sigma$ is known:

$$
\begin{aligned}
& \mathrm{X} \pm \mathrm{k \sigma}_{\mathrm{x}} \\
& \mathrm{X} \pm \mathrm{ks}_{\mathrm{x}}
\end{aligned}
$$

For example: For a given week, a random sample of 10 employees selected from a large group of hourly employees has a mean wage of $\mathrm{X}=180.00$ with a sample standard deviation of $s=14.00$. What is the interval of wages such that there is a least 95 percent confidence that the true mean is included within the interval? Using Chebyshev's inequality formula (8.10), since $1-1 / \mathrm{k} 2=$ 0.95 , we first solve for $\mathrm{k}$ :

$$
\begin{aligned}
& 1 / \mathrm{k}^{2}=1.00-0.95=0.05 \\
& 05 \mathrm{k}^{2}=1 \\
& \mathrm{k}^{2}=20
\end{aligned}
$$

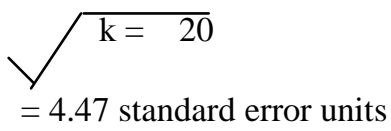

Then, from formula (8.12),

$$
\begin{aligned}
& X \pm \mathrm{k} \mathrm{s} / \sqrt{\mathrm{n}} \\
& 180 \pm 4.47(14) / \sqrt{10)}
\end{aligned}
$$

$180 \pm 4.47(4.43)=160.20$ TO 199.80

3. Instruments used in the gathering of primary and secondary data, such as the questionnaire and the financial documents, respectively:

Questionnaire:

The questionnaire gave a range of values for checking by the respondent for each element of a given variable, for example:

" 1 . What is the net income (parent) of your bank for 2004 ?

a) P 6, 668, 000, 000

b) P 3, 615, 226, 000

c) $\mathrm{P} 1,810,446,000$

d) $\mathrm{P} 2,275,135,000$

e) P1, 381, 025, 000

(Please see more in Exhibit A) f) others, please specify"

However, in the matter of measures to improve e-banking, the questions were coined in such a way that they have to be answered in essay, for example:

" 8 . What measure would you like to recommend to the national government to improve and to have effective internet banking?"

An example of the secondary source of data for validating the primary source is a bank's statement of condition. (Please see Exhibit B)

\section{Procedure in Data Gathering:}

The researcher personally handed-out questionnaires among the respondents. Three respondents sent their answers to the questionnaire via e-mail. The rest of the respondents (Two) sent to the researcher hard copies of the answered questionnaires. To validate the respondents answers, the researcher gathered secondary sources (Statement of Condition of the Bank, Please see Exh.B.) of the banks' financial data through the Security and Exchange Commissions' (SEC) research center.

5. Statistical Treatment of the research data:

This is the technical portion of the dissertation dealing with the adopted method of data measurement, their analysis, synthesis, and test of "goodness-of-fit" of the observed data on ROI to the regression equation's computed ROI to measure the equation's predictive capability:

The dependent variable data were in interval scale while the independent variable data were in binary scale. Per respondent, both the dependent variable datum in interval scale and the independent variable datum in binary scale were sorted written alongside each respondent's coded 
name in order to set up the Joint Observation Matrix which served as the form for enumerating the results of the inductive process involved in noting down each respondent's response in preparation for their synthesis using the Dummy Variable

Multiple Linear Regression [DVMLR] in order to come up with a generalization based on the set of joint observations composed of individual answers from all the respondents.(Please see Appendix A for the DVMLR procedure), the results of which were validated using SPSS 14 by using a common data-set of joint observations for both methods. The comparative direction of the beta coefficients of $X_{1}$ and $X_{3}$ (i.e., whether the beta coefficients algebraic signs in both the Best\&Kahn Method versus the SPSS are similar) in both methods are the same. In SPSS, the beta coefficient of $X_{2}$, instead of being negative as in Best \& Kahn, was even zero; hence, the general direction of the beta coefficients in both multiple linear regression methods were similar. Even the relative magnitudes of the beta coefficients in both methods were approximately similar, differing from each other by $13 \%$ only $(1.59$ vs. $1.38=0.2$ or $0.2 /$ $[\{1.59+1.38\} / 2]=0.2 / 1.48=0.13$ or $13 \%)$. [Please see Appendices A and A-1].

To address the matter of measuring the goodness- of-fit of the multiple linear regression equation, and its predictive capability, the Multivariate Standard Error of Estimate (MSEE) was used to test the null hypothesis on the goodness-of-fit of the model or the multiple linear regression equation itself.

(Please see Appendix A-1 for the application of the following MSEE formula on a multiple linear regression equation or model)

$$
\operatorname{MSEE}=\quad S_{Y^{\circ}=} \frac{\sqrt{ } \sum\left(Y^{\circ}-Y^{\circ}\right)^{2}}{n-(k+1)}
$$

Where $\mathrm{Y}^{\circ}$ - observed values of ROI

$\mathrm{Y}^{\circ}$ - computed values of ROI using the regression equation

$\mathrm{n}$ - number of sample respondent banks

$\mathrm{k}$ - number of explanatory variables

Synthesis using the Dummy Variable Multiple Linear Regression [DVMLR] in order to come up with a generalization based on the set of joint observations composed of individual answers from all the respondents.(Please see Appendix A for the DVMLR procedure).

Statistical Null Hypothesis: At 95\% confidence level, and Chebyshev's 4.5 standard error or 1.76 standard error assuming a normal distribution of the population among the values of the characteristic (Y) LESS THAN 95\% of THE SAMPLES' DEVIATIONS OF $\mathrm{Y}^{\circ}$ from $\mathrm{Y}^{\circ}$ FALLS BELOW THE (MSSE) MULTIPLE STANDARD ERROR OF ESTIMATE; HENCE, THE REGRESSION EQUATION CANNOT BE RELIED UPON TO GIVE AN ACCURATE PREDICTION OF THE VALUES OF
THE ROIS $\left(\mathrm{Y}^{\circ} \mathrm{s}\right)$ GIVEN THE VALUES ON INTERNET BANKING COMPLIANCE $\left(\mathrm{X}_{1}{ }^{\circ}\right)$, RATIO ON TOTAL BRANCHES $\left(\mathrm{X}_{2}^{\circ}\right)$, AND RATIO OF LENDING TO DEPOSIT LIABILITIES $\left(\mathrm{X}_{3}^{\circ}\right)$.

\section{RESULTS AND DISCUSSION}

Textual, Tabular or Graphic Presentation of Data, and Their Analysis:

How is the return on investment affected by changes in certain variables, such as internet banking compliance, ratio on total branches, and ratio of lending to deposit liabilities?

In the "factorial design's three-dimensional matrix" of the immediately preceding table, improving compliance with e-banking will not guarantee having an increase in ROI despite the increase in both its relative number of branches and loan-to-deposit ratio as in the case of bank $\mathbf{B}$.

Nonetheless, bank B's situation is worse than bank C's situation whereby the latter's ROI did not improve because it did not improve its e-banking compliance and neither both the relative size of its number of branches and ratio of loan-to-deposit.

But there was another case (bank D's case) where ROI increased when both the number of branches and the ratio of loan-to-deposit increased.

But certainly without internet banking (case of bank A), despite improvements in the relative number of branches and the ratio of loan-to-deposit, the ROI did not improve.

It was better to couple internet compliance with or either increasing the number of branches and increasing the relative size of loans-to-deposit as in the case of bank $\mathbf{E}$ which experienced an improvement in ROI. (Kinnear and Taylor, Marketing Research -An Applied Approach, 1991)

(Partial analysis): Pairing-in-twos of the dependent variable ROI with each independent variable:

a) ROI and improving a bank's e-banking compliance: Regarding the analysis that internet banking is the only one which has a positive impact on return on investment:

The successful implementation of internet banking yields a positive return on investment as in the case of bank E even when there is no increase in the number of its branches relative to the rest of the banks.

And also despite no increase in the ratio of its loans to deposit liabilities compared with the rest of the banks.

The clinching case is bank A's case, where e-banking did not improve and the ROI neither increased despite increases in the size of its number of branches and ratio of loan-to-deposit relative to the rest of the five banks.

In the case of bank D, the successful implementation of ebanking measured in terms of increases in its ROI was accompanied by the need to in-crease its branches relative to the rest of the banks as well as in the ratio of its loansto-deposit liabilities compared to the other banks.

In bank C's situation the latter's ROI did not improve because it did not improve its e-banking compliance and neither did both the size of its number of branches and ratio of loan-to-deposit relative to the rest of the five banks. 
b) ROI and increasing a bank's ratio of branches to all five banks' number of branches:

Regarding the analysis that the banks' use of branches to expand their horizon in reaching the clients has no impact on return-on-investment:

It means that increasing the number of branches as in the case of bank A and B (bank A had no improvement in its e-banking compliance unlike bank B but both increased their ratio of loans-to-deposit relative to the rest of the banks) did not help increase significantly the number of depositors with substantive deposits from which the banks sourced their loan able funds.

The exception, however was in the case of bank D whose increase in the number of its branches relative to the other banks generated substantive deposits from which the bank was able to draw funds for lending.

c) ROI and increasing the ratio of a bank's loans-todeposit liability relative to all five banks' ratio of loans-todeposit liabilities:

Regarding the analysis that increasing the ratio of lending to deposit liabilities compared to other banks --when considered as the definition of efficiency in order to increase the bank's income -- has no impact on their return on investment despite an improvement in e-banking compliance and increasing the ratio of its number of branches to total number of branches of all five banks (as in the case of banks A and B except bank A's lack of relative improvement in its e-banking compliance): It implies that increasing the ratio of loaned amounts-todeposit liabilities did not necessarily increase the banks' ROI unless the borrowers of the bank invested their borrowed funds in relatively high-yielding economic activities that enabled them to pay their loans to the bank as in the case of bank D. Unfortunately, banks A and $\mathrm{B}$, despite the increase in the ratio of their amounts loanedto-deposit liabilities compared to other banks did not have borrowers that wisely invested their borrowed funds from the banks in relatively high-yielding economic activities which could have enabled them to repay their loans to banks $\mathrm{A}$ and $\mathrm{B}$.

Synthesis:

To what extent ("extent" or impact refers to the value of the beta coefficient which has become comparative due to Kinnear and Taylor's treatment of the dependent variable $\mathrm{Y}$ and the independent variables $\mathrm{Xs}$ which express the latter in terms of the number of their standard errors) do the immediately preceding independent variables promote maximized returns on investment [dependent variable Y]?

Table XVII shows the coefficients $\left(\begin{array}{ll}b & s\end{array}\right)$ of the independent variables affecting the return on investment by changes in their levels (changes in the levels of the independent or explanatory variables such as internet banking compliance, ratio on total branches, and ratio of lending to deposit liabilities). [Please see computations of beta slope on Appendix A].

In Table $\mathbf{X V}$, the analysis showed that the internet banking compliance was the only factor positively affecting return on investment with a coefficient of
+0.3064 . The ratio of lending to deposit and the ratio on total branches revealed coefficients of -0.1917 and -0.1917 respectively.

\section{Table XV}

Result of the (DVLMR) Multiple Regression Analysis Revealing the Relationship between the Return on Investment and the Three Independent Variables

\begin{tabular}{|l|c|}
\hline \multicolumn{1}{|c|}{ Factors } & $\begin{array}{c}\text { Coefficient } \\
\mathbf{b}\end{array}$ \\
\hline Internet Banking $\left(\mathrm{X}_{1}{ }^{\circ}\right)$ & 0.3064 \\
\hline Ratio on Total Branches $\left(\mathrm{X}_{2}{ }^{\circ}\right)$ & -0.1917 \\
\hline Ratio of Lending to & -0.1917 \\
Deposit Liabilities $\left(\mathrm{X}_{3}{ }^{\circ}\right)$ & \\
\hline
\end{tabular}

The DVLMR looks as follows:

$$
\begin{aligned}
\mathrm{Y}^{\circ} & =\mathrm{a}+\mathrm{b}_{1} \mathrm{x}_{1}{ }^{\circ}+\mathrm{b}_{2} \mathrm{x}_{2}{ }^{\circ}+\mathrm{b}_{3} \mathrm{x}_{3}{ }^{\circ} \\
\mathrm{Y}^{\circ} & =0.0154+(0.3064) \mathrm{x}_{1}{ }^{\circ}+ \\
& (-0.1917) \mathrm{x}_{2}{ }^{\circ}+(-0.1917) \mathrm{x}_{3}{ }^{\circ}
\end{aligned}
$$

In using Kinnear and Taylor's treatment of dependent and independent variables as units of their standard errors, the beta coefficients are made comparable relative to each other. Hence, the beta coefficients when reflected in diagrammatic form appear as in the following Figure IV. Please observe that looking at Figure IV, the beta coefficient of Internet Banking Compliance as an explanatory or independent variable has a total of $516 \%$ (or $258 \%$ times two) net effect on ROI over the two other explanatory variables.

\section{Figure IV Beta Coefficients When Reflected In Diagrammatic Form}

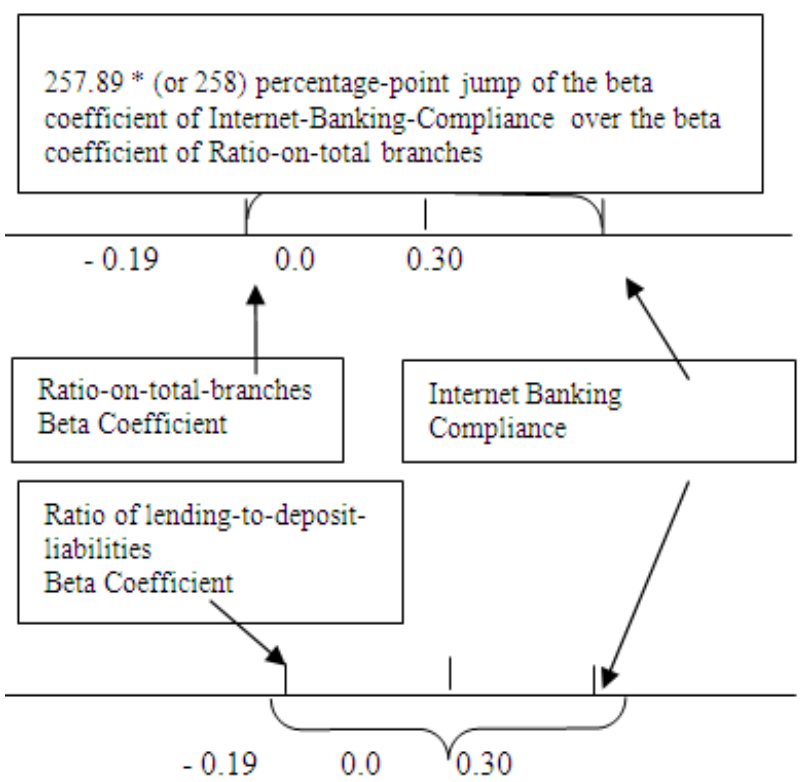

$257.89 *$ (or 258 ) percentage-point jump of the beta coefficient of Internet-Banking-Compliance over the beta coefficient of Ratio-of Lending-to-Deposit-Liabilities

$*|-0.19|+.30=.49$

$0.49 /|-.19|=2.58 ; 2.57 \times 100 \%=258 \%$ 
Accordingly, (Synthesis: wholistic analysis) the simultaneous pairing of all independent variables with the dependent variable ROI yields the following:

The net effect upon each independent variable of a simultaneous pairing of all independent variables with the dependent variable ROI is revealed in the beta coefficients of the multiple linear regressions to wit:

$$
\mathrm{Y}^{\circ}=0.0154+(0.3064) \mathrm{X}_{1}^{\circ}+(-0.1917) \mathrm{X}_{2}^{\circ}+(-0.1917) \mathrm{X}_{3}^{\circ}
$$

Please take note that the (synthesis: wholistic analysis) simultaneous pairing of all independent variables with the dependent variable ROI which is the synthesized version of the analytical pairing-in-twos (partial analysis) of each independent variable with the dependent variable ROI resulted in the following:

a) positive value $(+0.3064)$ of the beta coefficient of Internet Banking Compliance in relation to ROI. (Partial analysis): In the individual pairing of ROI with Internet Banking Compliance, as in the cases of bank D and E, the ROI increased as the latter increased but not in the case of bank B where the ROI went down. (Synthesis: wholistic analysis): Hence, since there were two cases of upward movement in ROI compared only to one instance of a decrease in ROI as the Internet Banking Compliance improved, the regression beta coefficient on Internet Banking Compliance turned positive in relation to movements in ROI;

b) Negative values (- 0.1917) of the beta coefficient of Ratio-on-Total Branches in its relationship to ROI. (Partial analysis): In the individual pairing of ROI with the Ratio-on-Total Branches, as in the case of bank D, the ROI increased as the latter increased but not in the case of banks A and B, where the ROI went down. (Synthesis: wholistic analysis): Hence, since there were two cases of downward movement in ROI compared only to one instance of an increase in ROI as the Ratio-on-Total Branches increased, the regression beta coefficient on Ratio-on-Total Branches turned negative in relation to movements in ROI.

c) Negative value (- 0.1917) of the beta coefficient Ratio of Lending-to-Deposit Liabilities in their relationship to ROI. (Partial analysis): In the individual pairing of ROI with the Ratio of Lending-to-Deposit Liabilities, as in the case of bank D, the ROI increased as the latter increased but not in the case of banks A and B where the ROI went down. (Synthesis: wholistic analysis):Hence, since there were two cases of downward movement in ROI compared only to one instance of an increase in ROI as the Ratio of Lending-to-Deposit Liabilities increased, the regression beta coefficient on Ratio of Lending-to-Deposit Liabilities turned negative in relation to movements in ROI.

What is the "goodness-of-fit" of the DVLMR measured in terms of its Multiple Standard Error of Estimate (MSEE= $\mathrm{Syx}_{\mathrm{n}}{ }^{*}$ ?) [Please see APPENDIX A-1]

* / The $\mathrm{Syx}_{\mathrm{n}}$ of 1.343724291 is higher than any of the differences between the $\mathrm{ROI}\left(\mathrm{Y}^{\circ}\right)$ and its computed values $\left(\mathrm{Y}^{\circ}\right)$; hence, all the samples' deviation of $\mathrm{Y}^{\circ}$ from $\mathrm{Y}^{\circ}$ are above the acceptable level of $68 \%$ of all samples for one standard error or which is above the acceptable level
Table XVIII

\section{The Difference between the Standardized ROI $\left(\mathrm{Y}^{\circ}\right)$ and the Computed Standardized ROI ( $\left.\mathrm{Y}^{\circ}{ }^{\circ}\right)$}

\begin{tabular}{|c|c|c|c|}
\hline Respondents & $\left(\mathrm{Y}^{\circ}-\mathrm{Y}^{\circ}\right)$ & Diff & $\sum\left(\mathrm{Y}^{\circ}-\mathrm{Y}^{\circ}\right)^{2}$ \\
\hline A & $\begin{array}{c}-0.9406- \\
(-0.6744)\end{array}$ & -0.2662 & 0.07086244 \\
& $\begin{array}{c}-0.6466- \\
(-0.0616)\end{array}$ & -0.585 & 0.342225 \\
\hline B & $\begin{array}{c}-0.4997- \\
0.0924\end{array}$ & -0.5921 & 0.35058241 \\
\hline C & $\begin{array}{c}0.6760- \\
(-0.0616)\end{array}$ & 0.7376 & 0.54405376 \\
& $1.4108-$ & 0.7056 & 0.49787136 \\
\hline E & 0.7052 & & \\
\hline
\end{tabular}

of $95 \%$ of all samples for 1.97 standard error using the premise of a normal distribution of the population (or which is above $95 \%$ of all samples for 4.5 standard error using Chebyshev's theorem). Hence, the DVLMR as determined by inputting the joint observation data has relatively high predictive capability.

\section{Interpretation Of The Partial Analysis and The Wholistic Analysis (synthesis):}

1. (Partial analysis): Pairing-in-twos of the dependent variable ROI with each independent variable:

--ROI and improving a bank's e-banking compliance: Regarding the analysis that internet banking is the only one which has a positive impact on return on investment: The successful implementation of internet banking yields a positive return on investment as in the case of bank E even when there is no increase in the number of its branches relative to the rest of the banks and also despite no increase in the ratio of its loans to deposit liabilities compared with the rest of the banks.

The clinching case is bank A's case, where e-banking did not improve and the ROI neither increased despite increases in the size of its number of branches and ratio of loan-to-deposit relative to the rest of the five banks.

In the case of bank D, the successful implementation of ebanking measured in terms of increases in its ROI was accompanied by the need to increase its branches relative to the rest of the banks as well as in the ratio of its loansto-deposit liabilities compared to the other banks.

In bank C's situation the latter's ROI did not improve because it did not improve its e-banking compliance and neither did both the size of its number of branches and ratio of loan-to-deposit relative to the rest of the five banks.

--ROI and increasing a bank's ratio of number of branches to all five banks' number of branches:

Regarding the analysis that the banks' use of branches to expand their horizon in reaching the clients has no impact on return-on-investment:

It means that increasing the number of branches as in the case of bank A and B (bank A had no improvement in its e-banking compliance unlike bank B but both increased their ratio of loans-to-deposit relative to the rest of the 
banks) did not help increase significantly the number of depositors with substantive deposits from which the banks sourced their loanable funds.

The exception however was in the case of bank D whose increase in the number of its branches relative to the other banks generated substantive deposits from which the bank was able to draw funds for lending.

--ROI and increasing the ratio of a bank's loans-to-deposit liability relative to all five banks' ratio of loans-to-deposit liabilities :

Regarding the analysis that increasing the ratio of lending to deposit liabilities compared to other banks --when considered as the definition of efficiency in order to increase the bank's income -- has no impact on their return on investment despite an improvement in e-banking compliance and increasing the ratio of its number of branches to total number of branches of all five banks (as in the case of banks A and B except bank A's lack of relative improvement in its e-banking compliance):

It implies that increasing the ratio of loaned amounts-todeposit liabilities did not necessarily increase the banks' ROI unless the borrowers of the bank invested their borrowed funds in relatively high-yielding economic activities that enabled them to pay their loans to the bank as in the case of bank D. Unfortunately, banks A and B, despite the increase in the ratio of their amounts loaned-todeposit liabilities compared to other banks did not have borrowers that wisely invested their borrowed funds from the banks in relatively high-yielding economic activities which could have enabled them to repay their loans to banks A and B.

2. (Synthesis: wholistic analysis): Simultaneous pairing of all independent variables with the dependent variable ROI:

The net effect upon each independent variable of a simultaneous pairing of all independent variables with the dependent variable ROI is revealed in the beta coefficients of the multiple linear regression to wit:

$\mathrm{Y}^{\circ}=0.0154+(0.3064) \mathrm{x}_{1}{ }^{\circ}+(-0.1917) \mathrm{x}_{2}{ }^{\circ}+(-0.1917) \mathrm{x}_{3}{ }^{\circ}$

\begin{tabular}{|l|l|}
\hline \multicolumn{1}{|c|}{ Factors } & $\begin{array}{l}\text { Regression } \\
\text { Coefficient b }\end{array}$ \\
\hline Internet Banking Compliance $\left(\mathrm{X}_{1}{ }^{\circ}\right)$ & +0.3064 \\
\hline $\begin{array}{l}\text { Ratio on Total Branches } \\
\left(\mathrm{X}_{2}^{\circ}\right)\end{array}$ & -0.1917 \\
\hline $\begin{array}{l}\text { Ratio of Lending to Deposit } \\
\text { Liabilities }\left(\mathrm{X}_{3}{ }^{\circ}\right)\end{array}$ & -0.1917 \\
\hline
\end{tabular}

Please take note that the simultaneous pairing of all independent variables with the dependent variable ROI which is the synthesized version of the analytical pairingin-twos of each independent variable with the dependent variable ROI resulted in the following:

a) Positive value of the beta coefficient $(+0.3064)$ of Internet Banking Compliance in relation to ROI. In the individual pairing of ROI with Internet Banking Compliance, as in the cases of banks D and E, the ROI increased as the latter increased but not in the case of bank
B where the ROI went down. Hence, since there were two cases of upward movement in ROI compared only to one instance of a decrease in ROI as the Internet Banking Compliance improved, the regression beta coefficient on Internet Banking Compliance turned positive in relation to movements in ROI;

b) negative values of the beta coefficient (- 0.1917) of Ratio-on-Total Branches in its relationship to ROI. In the individual pairing of ROI with the Ratio-on-Total Branches, as in the case of bank D, the ROI increased as the latter increased but not in the case of banks A and B where the ROI went down. Hence, since there were two cases of downward movement in ROI compared only to one instance of an increase in ROI as the Ratio-on-Total Branches increased, the regression beta coefficient on Ratio-on-Total Branches turned negative in relation to movements in ROI.

c) Negative values of the beta coefficient (- 0.1917) of Ratio of Lending-to-Deposit Liabilities in its relationship to ROI. In the individual pairing of ROI with the Ratio of Lending-to-Deposit Liabilities, as in the case of bank D, the ROI increased as the latter increased; but not in the case of banks A and B where the ROI went down. Hence, since there were two cases of downward movement in ROI compared only to one instance of an increase in ROI as the Ratio of Lending-to-Deposit Liabilities increased, the regression beta coefficient on Ratio of Lending-to-Deposit Liabilities turned negative in relation to movements in ROI.

\section{CONCLUSION}

The study at hand, revealed the following findings

1. Hypothesis Test: At a confidence level of $95 \%$, all of the deviations of $\mathrm{Y}^{\circ}(\mathrm{ROI})$ from the computed $\mathrm{ROI}\left(\mathrm{Y}^{\circ}{ }^{\prime}\right)$ are less than 1.343724291 (Multiple Standard Error of Estimate $=\mathrm{Syx}_{\mathrm{n}}$ ) which means all the samples (observed values) are within Chebyshev's 4.5 standard error or at $68 \%$ confidence level are within one standard error (using a Normal Distribution premise) which is above the acceptable level of $95 \%$ and $68 \%$ of all samples for Chebyshev's theorem and the normal distribution premise respectively.

In Table XV, the analysis showed that the internet banking compliance was the only factor positively affecting return on investment with a coefficient of +0.3064 . The ratio of lending to depositn liabilities and the ratio on total branches revealed coefficients of -0.1917 and -0.1917 respectively.

As a result of the findings on the test-of-hypothesis, the predictive capability of the multiple linear regression equation was established in terms of determining the Banks' ROI given the changes in the values of the three independent variables namely:

e-banking compliance, ratio of the number of branches of a bank relative to the total number of branches of all the five banks, and the ratio of amounts loaned to deposit liabilities of a bank relative to the ratios of the other banks. 
That internet banking is the only one which has a positive impact on return on investment. The successful implementation of internet banking yields a positive return on investment.

That the banks' use of branches to expand their horizon in reaching the clients has no impact on return on investment. Ratio-to-total branches have no impact on return on investment. It means that increasing the number of branches does not help increase significantly the number of depositors and their deposits.

Ratio of lending to deposit liabilities, when considered as the definition of efficiency in order to increase the income of the FIVE universal banks, has no impact on return on investment unless such loans by the borrowers yielded relatively high returns which enabled them to repay the banks.

\section{REFERENCES}

[1] Livingstone, MBA in Finance and Accounting, 1992

[2] Newman, Logan and Hegarty, Strategy, 1989

[3] International Student Edition, Computers Tools for an information Age, H.L. Capron, 2005

[4] Republic of the Philippines, Congress of the Philippines, Metro Manila, Eleventh Congress, Second Regular Session, 1999

[5] Current Status and Issues of e-government in the Philippines

[6] Republic Act No. 8792, 1999

[7] Banko Sentral Review, 2000

[8] Philippine Banking Almanac IV, 2000

[9] Supervisory Reports \& Studies Office, Supervision and Examination Sector

[10] http://www.american.edu/carmel/bree/internet.html

[11] Bree Conally. (1999). "Impacts of National Information Technology Environments on Business, Kogod School of Business, American Society", Washington, D.C.

[12] Ongkasuwan, Metta. (2002). "A Comparative Study of Internet Banking in Thailand"

[13] http://www.mictimes.net, 2002

[14] Laudon, K. \& Traver, C. (2010). "E-Commerce 2010, Business, Technology, Society"

[15] Kinnear and Taylor. (1987). "Marketing Research" 